\title{
Influence of Horizontal and Vertical Barriers on Fire Development for Ventilated Façades
}

\author{
Antonela Čolić (D*, Faculty of Civil Engineering, University of Zagreb, Zagreb, \\ Croatia \\ Ivana Banjad Pečur, Department of Materials, Faculty of Civil Engineering, \\ University of Zagreb, Fra Andrije Kačića Miošića Street, Nr. 26, Zagreb, \\ Croatia
}

Received: 4 February 2019/Accepted: 9 January 2020

\begin{abstract}
Although using various innovative materials for ventilated facade systems positively contribute to the energy efficiency of buildings, the application of such materials can also pose a certain risk of fire propagation through the façade. In the last decade, medium and large-scale tests, as well as numerical analysis have been performed to assess the impact of fire barriers on fire propagation through ventilated façades. However, the number of fire barriers and their specific positions can also have an effect on the fire safety of facades, which has not been studied. Consequently, the question arises whether real fire exposure on a façade can be adequately simulated and analysed in sufficient detail, by using large-scale testing methods. This paper aims to conduct a parametric analysis on a broader range of large-scale samples by using the procedure given in the standard BS 8414-1:2015 + A1:2017. To understand better the impact of the number and position of cavity barriers for different types of insulation materials (stone wool/PIR/phenolic foam) used in modern façade systems with non-combustible cladding (ACM-A2). Seven tests were carried out in Croatia between October 2017 and April 2018. In the case of combustible insulation, two horizontal barriers were insufficient in preventing fire propagation. Temperatures accumulated above $600^{\circ} \mathrm{C}$, reaching $840^{\circ} \mathrm{C}$ in PIR insulation and $979^{\circ} \mathrm{C}$ in phenolic foam insulation. For the same sample designed with non-combustible insulation, the maximum temperature measured was $133^{\circ} \mathrm{C}$. Facades with combustible insulation passed the test only when four horizontal barriers were used. The existence of vertical barriers had a positive impact on preventing the fire propagation because the insulation on the left side of the chamber, behind the vertical barrier, remained undamaged. Vertical barriers on the right side of the chamber delayed the horizontal fire propagation from the main wall to the wing wall depending on the type of insulation. The results from these tests can serve as a basis for future research on the effects of fire barriers on fire propagation.
\end{abstract}

Keywords: Ventilated façade, Cavity barriers, Combustible insulation, Large-scale tests, Fire spread

\footnotetext{
* Correspondence should be addressed to: Antonela Čolić, E-mail: colicantonela7@gmail.com
} 


\section{Introduction}

The development of technology has brought various types of materials into the production of ventilated facades. Application of various innovative systems, on the one hand, have good properties in terms of energy efficiency, but on the other hand, they can introduce a risk of contribution to fire spread along facades. The purpose of this paper is to conduct a parameter analysis on a larger range of samples to understand better the impact of the position of cavity barriers and assess the influence of the type of insulation material used.

Following significant ventilated facades' fires, the difference in installation details and position of cavity barriers was noticed. For example, in Knowsley Heights fire [1] (Liverpool, the UK, 1991), there were no fire barriers in the air cavity behind the cladding. Another example is Grenfell Tower [2] (London, the UK, 2017), where barriers were present, but the geometry and the installation details of the cladding system created an interconnected network of cladding cavities which allowed the fire to spread quickly. In the TVCC tower [3] (Beijing, China, 2009) barriers were not installed and both the insulation and the cladding were combustible. This fire resulted in the change of the Chinese regulations specifying that the use of spandrels and horizontal fire stops at the floor perimeter shall also be added to the existing codes [4]. In the Lacrosse building (Melbourne, Australia, 2014) aluminium composite panels with a polyethylene core were installed on the sidewall of the balcony, and from the final report, it can be concluded that barriers were not used [5]. For the two fire incidents The Torch (2015) and The Address Tower (2016) (Dubai, the UAE) the existence of fire barriers remains unknown, but in both cases, the cladding was made of combustible materials [7]. All the fires mentioned in this paragraph involved combustible cladding. However, the aim of this paper is to show the differences in fire propagation between the ventilated façade systems with non-combustible cladding but with different types of insulation, andthe impact of both vertical and horizontal fire barriers.

\subsection{Considered Methods}

Since fire barriers are a part of ventilated façade systems, it is very important to know what kind of testing method is being used to ensure that the building can be treated as safe in the event of fire [8]. Fire test methods and the generated data must be assessed and evaluated to determine whether the specific test conditions are applicable for the specific fire scenario or the final use of the tested sample [9]. For this paper, literature on the analysis of fire propagation and influence of barriers for three methods was reviewed: numerical analysis, medium-scale, and large-scale testing.

1.1.1. Numerical Analysis One of the main advantages of numerical simulation is the ability of studying a number of aspects of the fire propagation avoiding the high costs of laboratory tests [10, 11]. In computer-simulation study, Giraldo et al. [10] have given a representative image of the spread of fire depending on the barrier type and characteristics, insulation, and the width of the air cavity. Even when non-combustible insulation was used, their study demonstrated that smoke 
and flame will spread through the cavity of the ventilated facade if horizontal barriers are not used. Barriers placed on window edges make it difficult for the fire to go from the inflamed space into the inside of the ventilated facade and back, but do not prevent the flame from reaching the surface of the facade where the fire can freely spread. The importance of non-combustible cladding must be emphasized in this case. Proper design should, on top of the barriers on window edges, plan for horizontal barriers on floor slabs.

1.1.2. Medium-Scale Testing Medium-scale testing results may be used for the development of products and indication of material behaviour with the advantage of not being as costly as large-scale tests. However, they are often incomparable with the large-scale testing, due to lower fire exposure and less embedded construction details for the use in the elements such as joints, barriers, etc. [1].

The test conducted according to the standard ISO 13785-1 [12] is the example of a medium-scale test. The effects of cavity barriers, aluminium composite panels as claddings, and several insulation materials were observed on nine samples. In the research by Guillaume et al., it is shown that cavity barriers were largely ineffectual in the three tests with the combustible ACM-PE cladding, but they showed good results when being combined with the non-combustible ACM-A2 cladding. They also state that mineral wool and phenolic foam insulation have shown similar behaviour when the fire retardant ACM-FR and the non-combustible ACMA2 cladding is used. Their results for the ACM-PE based cladding compositions also confirmed the results obtained during the BS 8414-1 DCLG tests [13-16].

However, authors believe that such comparison, in general, should be done carefully since many other parameters should be considered when testing the fire performance of facades. Although correlation is not evident, all scales can give important details. For the good rules of extension of application, there is a need to develop a decision scheme based on both scales to be able to accommodate all variations in facade systems. Performing intermediate-scale tests can be a good way to complete assessments performed at large-scale but it is not only about combining the individual test results into system that is more complex, it is about the reliability and the validation of the tests methods being applied in the first place. It is important to develop the skills to be able to properly assess the results.

1.1.3. Large-Scale Testing Large-scale testing is often seen as the most representative way of showing the full performance of a building during fire as long as it is well designed and constructed. Numerous large-scale test methods exist in Europe and North America but we are still missing an harmonized test method for Europe [17]. In the work reported by RISE, together with a group of laboratories [18], authors explained how the repeatability and reproducibility of test methods, as well as this harmonisation, can be maintained. They suggest that a possible solution could be to define a heat exposure curve, as for fire resistance testing. They propose the usage of gas burners that can be regulated instead of using a defined amount of free burning fuel and advise to use plate thermometers to measure the heat exposure on the façade instead of conventional thermocouples. Advices proposed by RISE is very promising but still under evaluation. 
As early as in 1986, Jeffs et al. conducted large-scale testing using the French standard from 1964 [19]. Even then, the significance of fire barriers was noticed. Researchers stated that in tall buildings, it is necessary to prevent the fire spread by using adequately designed construction details. They also noticed that fire propagation along the facade, as well as its penetration into the neighbouring fire compartments (flats), could be prevented by using barriers in the shape of horizontal fasteners for ventilated facade cladding. Another research conducted by Kolaitis et al. [20] investigated the main aerodynamic and thermal phenomena which influence the flow of hot gasses and flames through the cavities of ventilated facade systems. Fire barriers were not installed, which is the "worst-case scenario" for the system without flammable materials. The researchers also concluded that regulation was not good enough in defining the use and positioning of barriers essential for ventilated facades (because the flame moves unnoticed through the cavity). The real fire exposure brings in question the open-state barriers used in façade systems today, and this fire scenario is not adequately simulated by any of the large-scale tests. Currently the barriers can be examined using the North American method at a bench scale ASTM E2912-1.

Tamás Bánky and Hideki Yoshioka, authors from Hungary and Japan performed their tests using identical "aluminum composite panel" specimens provided by the same supplier and tested it with two national standards. Almost identical specimen with aluminum composite panel façade, ventilated layer and rock wool insulation installed, has passed the criteria of MSZ 14800-6 (large-scale Hungary standard) but failed the criteria of JIS A 1310: 2019 (intermediate-scale Japan standard).

Reviewing the available literature, it can be concluded that Europe should set up an adequate fire barrier test so that one test can be applied for both composites such as ETICS and ventilated façades (or elsewhere - CLT-based façades, curtain façades, etc.). Fire spread along the wall exterior surface is not part of the European rating system and remains subjected to national fire protection regulations. Numerous test methods covered by this scenario exist in Europe and North America at national level and they are compared in [17]. The European Commission contracted a consortium led by RISE to develop a harmonised European test for façades with varied requirements based not only on fire spread, but also on falling parts, burning debris, smouldering fire, smoke and detailing (windows) [21]. Two methods have been proposed, one simply keeping two existing tests (BS8414 and DIN 4102-20) and an alternative method proposing several changes that can address some of the weak points of the two methods. The outcome of the report was an tender for the EU Commission to continue the work on the alternative method and so is therefore relevant to discuss the weak points BS 8414. The setup and technical specifications of new European test standard together with the fire exposure in a new test method through numerical simulation was discussed during the 3rd International Symposium on Fire Safety of Facades-FSF2019 [22]. However, one of the most important questions which arose were, what kind of safety should be obtained and is the one standard test and classification enough? It is not feasible to test all combinations of different products or system characteristics for their reaction to fire or fire resistance performances, but it is important to 
know that such characteristics can substantially influence a test result. The potential of façade being safe is highly dependent on which risk is to be assessed and one should be aware that tests in laboratory are made under perfect and controlled conditions where "standardized" fire scenario is used. Detailing is difficult to evaluate, and more complex geometries are difficult to be assessed by using only one method.

Following the Grenfell fire public investigation [2, 23], Lane [24] noticed that the BS 8414 Parts 1 and 2 ought to include window openings and other relevant fixtures and fittings. Lane also states that a more robust testing framework, reflecting the real building design and construction detailing, would also assist in establishing whether materials of "limited combustibility" are suitable. According to the report from Torero [23], such tests provide a single scenario consistent with an external fire, has very limited number of measurements and a simple failure criterion, which is not adapted to the complexity of a real fire scenario.

Based on the research by Lane and the tests carried out for this research, we assess that fire barriers can radically alter test performance, but the number and location are unspecified in the standard BS 8414. However, the use of fire barriers is implied by the requirement to report any barrier failure during the test. It is important to mention that it is not enough to describe its behaviour after testing because the failure of cavity barriers will appear in the manufacturer's test report, but this information may not be conveyed to the fire risk assessor or end user. Another important assumption is that cavity barriers must be identical to that in the façade design used in real buildings and thus façade tests should also include openings such as windows or doors. Otherwise, composite design for the test is insufficiently detailed. Because of that, standard BS 8414 should include a failure criterion, such as "any fire penetration through cavity barriers incorporated within the cladding system, or around it through breaches in the external cladding panels."

The aim of this research is to examine the preferred number and position of barriers in the design of ventilated façades and to assess the impact of combining the fire barriers with the combustible and non-combustible insulation on the fire spread. The tests were performed outdoors, according to the environmental conditions specified in the BS 8414-1 [26], and the duration of the test was $60 \mathrm{~min}$. Some of the samples consist of the same elements (insulation and cladding) as in the DCLG tests ordered by the UK government [13-16], but DCLG tests were examined indoors and extinguished as soon as the BR135 criterion failed.

It must be noted that for this research, we focused on a large number of different tests and each system was tested only once due to the limited financial resources. The large-scale sample behaviour in the standard testing always differs from the real fire scenario, but it allows for the comparability of the repeated tests. Therefore, the results can serve as a basis for comparison for other researchers, which ultimately guides the update of the existing standards and thus the possibilities of implementation in the recommendations for the design and execution of such ventilated facade systems. 


\section{Experimental Method}

For this analysis, ventilated façade systems tests were performed at the LTM laboratory in Croatia between October 2017 and April 2018. Samples were tested using the British standard "BS 8414-1, Fire performance of external cladding systems - Part 1:.", "'(..) a test method for determining the fire performance characteristics of non-loadbearing external cladding systems, rainscreen overcladding systems and external wall insulation systems when applied to the face of a building and exposed to an external fire under controlled conditions [26]".

There are three typical scenarios of fire spread over façades, where BS 8414-1 is a physical model of a given scenario where an internal fire has started in a compartment inside a building. Two other scenarios are, when fire spread of the external fire is caused by radiation from the neighbouring, building or when the source of fire is located next to the façade, with the consequence of radiation or direct exposure to fire (litter on the balcony, parked cars).

Several different tests were performed but we have focused on seven samples where all of them have the same cladding (ACM-A2) and the same main parameters but varied in the number of barriers and the type of insulation. An external cladding system is consisted of aluminium substructure, insulation, cavity, all joints and coating. Figure 1, and define the position of thermocouples in front of the face of cladding system and in each layer. Thermocouples at level 1 are located $250 \mathrm{~cm}$ from the top of combustion chamber, while the position of level 2 is at $500 \mathrm{~cm}$ from the top of combustion chamber.

During the tests, the ability of ventilated façade to resist to the propagation of fire was observed. We tracked the temperatures on both levels and we weighted the falling debris.

Failure according to BR135 due to external/internal fire spread is deemed to have occurred if the temperature of any of the external/internal thermocouples at

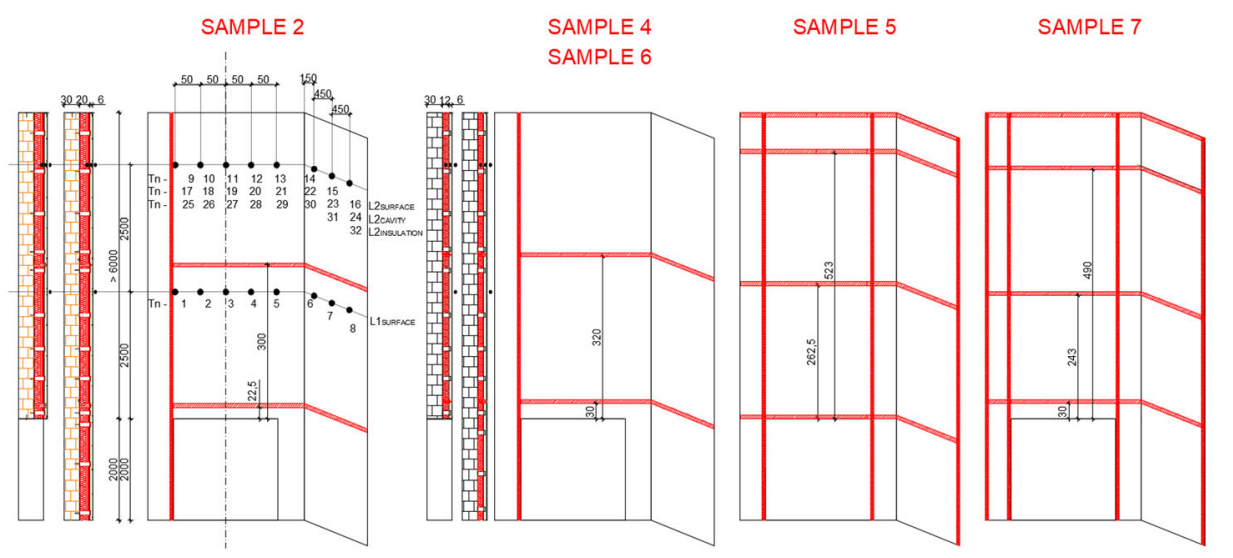

Figure 1. Schematic of test apparatus, position of external and internal (cavity and insulation) thermocouples, horizontal and vertical barriers. 


\section{Table 1}

Examined Groups of Samples

\begin{tabular}{llllll}
\hline Group & Sample & Insulation & Cladding & Horizontal barriers & Vertical barriers \\
\hline 1 & 1 & Stone wool & ACM A2 & NO & NO \\
& 2 & Stone wool & & 2 & 1 \\
2 & 3 & PIR & NO & NO \\
& 4 & PIR & 2 & 1 \\
& 5 & PIR & & 4 & 3 \\
3 & 6 & Phenolic foam & & 2 & 1 \\
& 7 & Phenolic foam & & 4 & 4 \\
\hline
\end{tabular}

level 2 rise above $\mathrm{Ts}^{1}$ and thus exceeds $600^{\circ} \mathrm{C}$ for a period of at least $30 \mathrm{~s}$ within 15 min of the start time (ts).

The test duration was 60 min unless the flame spread extended above the test apparatus, which is a criterion for early termination of the test, or if there is a risk to the safety of personnel or impending damage to equipment (but the test was continued at the sponsor's request for detailed observation of specimen behaviour).

No failure criteria are defined for mechanical performance. However, all details of any system damage such as total collapse, spalling, delamination, flaming debris and pool fires, etc. was described and considered in the overall risk assessment of the specimen tested.

\section{Materials}

Seven specimens were divided into three groups with different components were examined. Samples consist of the components shown in Table 1 the following table:

Each sample was built following the list of materials listed below in Tables 2, and 3. For all samples the insulation varies (the third component in the Table 2) while other components, apart from their dimensions, remain the same (Fig. 2).

Figures 1 and 3 show the position of the thermocouple relative to the position of the barrier for easier result monitoring. Samples 1 and 3 are not shown because they do not have any horizontal nor vertical barriers. Thermocouples are positioned as follows: $\mathrm{Tn}-1-\mathrm{Tn}-\mathrm{T} 8$ are $50 \mathrm{~mm}$ from the external panel on level one, Tn-9-Tn-16 are $50 \mathrm{~mm}$ from the external panel on level two, Tn-17-Tn-24 at the midpoint of the air cavity layer on level two and Tn-25-Tn-32 at the midpoint of the insulation on level two. To describe a thermocouple position, following abbreviations will be used (Fig. 3).

L1_S for surface at level one, L2_S for surface at level two, L2_C for cavity layer at level two and L2_I for insulation layer at level two.

\footnotetext{
${ }^{1}$ Mean temperature of the thermocouples at level 1 during the $5 \mathrm{~min}$ before ignition.
} 


\section{Table 2}

Material Components

\begin{tabular}{|c|c|c|c|}
\hline Pos. & Name & Material & Dimensions \\
\hline 1. & Sample 1,2: aluminium wall "L" bracket & Aluminium & $1 / \mathrm{w} / \mathrm{h}=215 / 68 / 86 \mathrm{~mm}$ \\
\hline 1. & Sample 3-7: aluminium wall "L" bracket & Aluminium & $\mathrm{l} / \mathrm{w} / \mathrm{h}=155 / 68 / 86 \mathrm{~mm}$ \\
\hline 2. & $\begin{array}{l}\text { Steel screws with plastic anchor (wall } \\
\text { and "L" bracket connection) }\end{array}$ & Steel & $\varnothing 10 \times 80 \mathrm{~mm}$ \\
\hline 3. & $\begin{array}{l}\text { Sample 1,2: Mineral (stone) wool insulation } \\
\text { panels (Fig. 2) }\end{array}$ & $\begin{array}{l}\text { Mineral } \\
\quad \text { (stone) wool }\end{array}$ & $\begin{array}{l}1 \times \mathrm{w}=1000 / 610 \mathrm{~mm} \\
\mathrm{~d}=150 \text { and } 50 \mathrm{~mm}\end{array}$ \\
\hline 3. & $\begin{array}{l}\text { Sample 3-5: Polyisocyanurate insulation PIR } \\
\text { panels with aluminium foil on face on both } \\
\text { sides filled with polyurethane foam (Fig. 2) }\end{array}$ & PIR & $\begin{array}{l}\mathrm{l} \times \mathrm{w}=1000 / 610 \mathrm{~mm} \\
\mathrm{~d}=120 \mathrm{~mm}\end{array}$ \\
\hline 3. & $\begin{array}{l}\text { Sample 6-7: Phenolic foam insulation panels } \\
\text { with fiberglass foil on both sides; spaces fil- } \\
\text { led with polyurethane foam (Fig. 2) }\end{array}$ & Phenolic foam & $\begin{array}{l}1 \times \mathrm{w}=1200 / 2400 \mathrm{~mm} \\
\mathrm{~d}=120 \mathrm{~mm}\end{array}$ \\
\hline 4. & Plastic anchors with caps & Plastic & $\varnothing 90 / 8 \times 200 \mathrm{~mm}$ \\
\hline 5. & aluminium "L" profiles & Aluminium & $\begin{array}{l}\mathrm{w} / \mathrm{h} / \mathrm{t}=60 / 40 / 1.8 \mathrm{~mm} \\
1=6 \mathrm{~mm} \text { (cut to measure) }\end{array}$ \\
\hline 6. & aluminium " $\mathrm{T}$ " profiles & Aluminium & $\begin{array}{l}\mathrm{w} / \mathrm{h} / \mathrm{t}=100 / 60 / 1,8 \mathrm{~mm} \\
1=6 \mathrm{~m}(\text { cut to measure })\end{array}$ \\
\hline 7. & Self-tapping stainless steel screws & Stainless steel & $\varnothing 5,5 \times 19 \mathrm{~mm}$ \\
\hline 8. & $\begin{array}{l}\text { Sample 2: Horizontal mineral wool barrier } \\
\text { with expanding gasket EI } 30 / 30 \mathrm{~min}\end{array}$ & $\begin{array}{l}\text { Mineral } \\
\text { (stone) wool }\end{array}$ & $\begin{array}{l}1 \times \mathrm{w}=1000 \times 225 \mathrm{~mm} \\
\mathrm{~d}=75 \mathrm{~mm}\end{array}$ \\
\hline 8. & $\begin{array}{l}\text { Sample 4-7: Horizontal mineral wool barrier } \\
\text { with expanding gasket EI } 30 / 30 \mathrm{~min}\end{array}$ & $\begin{array}{l}\text { Mineral } \\
\quad \text { (stone) wool }\end{array}$ & $\begin{array}{l}1 \times \mathrm{w}=1000 \times 145 \mathrm{~mm} \\
\mathrm{~d}=75 \mathrm{~mm}\end{array}$ \\
\hline 9. & $\begin{array}{l}\text { Sample 2: Vertical mineral wool barrier with } \\
\text { fire barrier foil }\end{array}$ & $\begin{array}{l}\text { Mineral } \\
\text { (stone) wool }\end{array}$ & $\begin{array}{l}1 \times \mathrm{w}=1000 \times 260 \mathrm{~mm} \\
\mathrm{~d}=75 \mathrm{~mm}\end{array}$ \\
\hline 9. & $\begin{array}{l}\text { Sample 4-7: Vertical mineral wool barrier } \\
\text { with fire barrier foil }\end{array}$ & $\begin{array}{l}\text { Mineral } \\
\text { (stone) wool }\end{array}$ & $\begin{array}{l}1 \times \mathrm{w}=1000 \times 180 \mathrm{~mm} \\
\mathrm{~d}=75 \mathrm{~mm}\end{array}$ \\
\hline 10. & Steel fixing brackets & Steel & $1 \times \mathrm{w}=235 \times 25 \mathrm{~mm}$ \\
\hline 11. & Steel screws with plastic anchor & Steel & $\varnothing 3 \times 25 \mathrm{~mm}$ \\
\hline 12. & $\begin{array}{l}\text { Sample 1-7: Panel coatings of aluminium } \\
\text { composite material (ACM-A2) }\end{array}$ & $\begin{array}{l}\text { Aluminium } \\
\text { composite }\end{array}$ & $\begin{array}{l}1 \times \mathrm{w}=4050 \times 1500 \mathrm{~mm} \\
\mathrm{~d}=4 \mathrm{~mm} \text { (cut to measure) }\end{array}$ \\
\hline 13. & Stainless steel rivets & Stainless steel & $\varnothing 5 \times 16 \mathrm{~mm}$ \\
\hline 16. & Sample 3-7: Self-adhesive metallized tape & Polypropylene & $\mathrm{w}=75 \mathrm{~mm}$ \\
\hline
\end{tabular}

\section{Table 3}

\section{Insulation Details}

\begin{tabular}{|c|c|c|c|}
\hline Insulation (3) & Stone wool & PIR & Phenolic foam \\
\hline Density $\left[\mathrm{kg} / \mathrm{m}^{3}\right]$ & 50 & 30 & 35 \\
\hline Surface finish & - & Aluminium foil & Aluminium foil \\
\hline Edge detail & Straight & & \\
\hline Thermal conductivity $\lambda(\mathrm{W} / \mathrm{mK})$ & 0.035 & 0.022 & 0.020 \\
\hline Reaction to fire & $\mathrm{A} 1$ & $\mathrm{E}$ & $\mathrm{B}, \mathrm{s} 1-\mathrm{d} 0$ \\
\hline
\end{tabular}



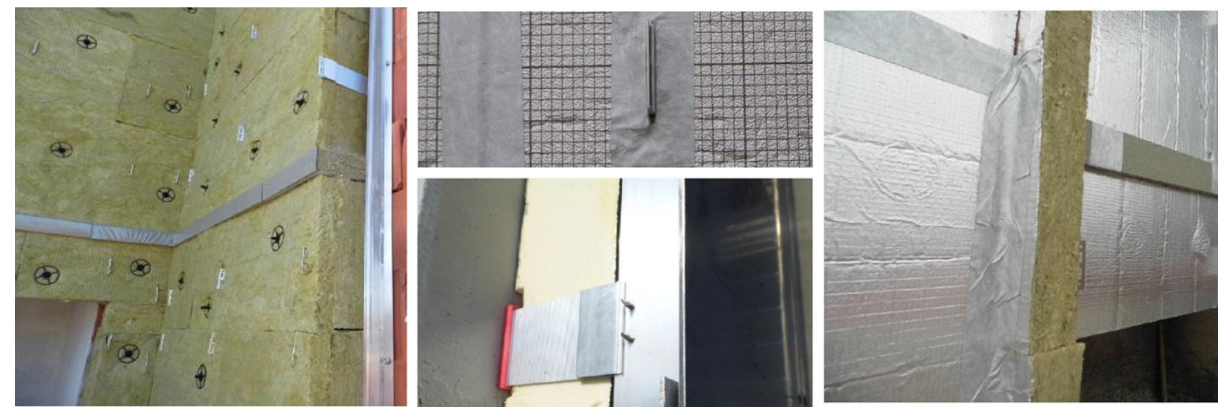

Figure 2. Stone wool (left: Sample 1-2), PIR (middle Sample 3-5), Phenolic foam (right: Sample 6-7).
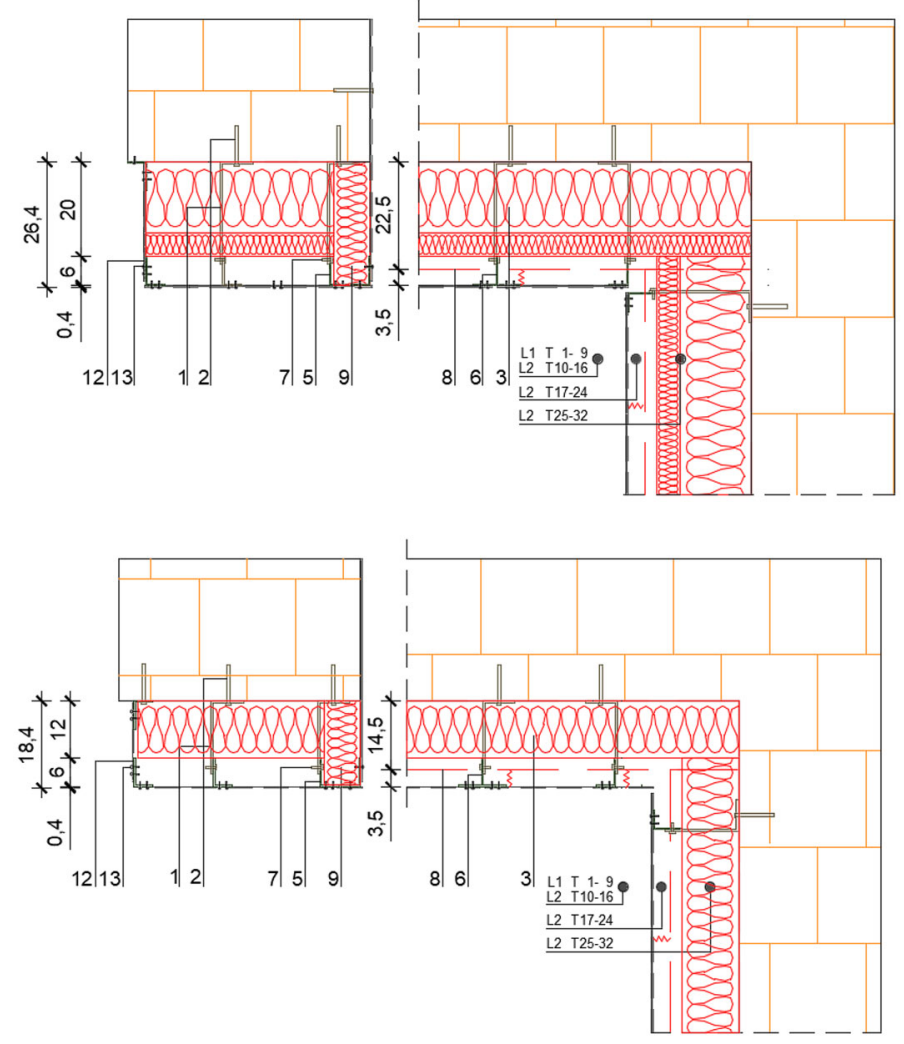

Figure 3. Wall corner detail with material specifications (Table 2) and with thermocouples; Sample 2 (above), Sample 4,6 (below) (dimensions in cm). 
An open-state horizontal barrier (HB) consists of high density mineral wool and expanding foil on one edge designed to keep the ventilated façade "open" with the spiral fixing elements which maintain the gap between the barrier and the outer finishing. This allows the product to maintain ventilation and drainage of cavities under normal conditions of use, while in case of fire the foil suddenly expands outward to close the cavity and prevent the passage of fire and smoke. It is installed horizontally (Fig. 1, "Appendix"-Tables 9, 11 and Fig. 17) and provides a width gap of up to $300 \mathrm{~mm}$. Horizontal barriers are produced in a length of $1000 \mathrm{~mm}$ and $75 \mathrm{~mm}$ thick. The distance between the horizontal barrier and the final lining, i.e. the width of the air cavity at the horizontal barrier location is $35 \mathrm{~mm}(2)$.

The vertical barrier (VB) is designed to fully close the ventilated façade cavity. It secures lateral compression for horizontal moving motion (air/smoke/flame) and is made without expanding foil. It is delivered in one-part, allowing easy cutting and installation. This barrier is not intended for horizontal application. It can assure EI60 (cavity $<300 \mathrm{~mm}$ ) or EI120 for cavities of 300-1000 mm. Its thickness is $75 \mathrm{~mm}$, placed on the main wall along the entire height (Fig. 1, "Appendix"Table 10), fixed by steel carriers.

Aluminium composite panels consist of two coil-coated aluminium sheets that are laminated on both sides of an A2 core. Panels are flat and riveted and Table 10 is a label for mineral filling with limited combustibility. ${ }^{2}$ The core is tested by standard BS EN ISO 1716: 2010, which classifies products in grades from 1 to $3[13-16,28]$.

\section{Results}

The results are divided in two sections, showing the behaviour of the Samples during the first $15 \mathrm{~min}$ and the full $60 \mathrm{~min}$. For the first $15 \mathrm{~min}$, the temperatures were recorded to determine if the Sample has passed or failed the test, according to the fire spread criterion set by BR135. For the second section, the highest temperatures recorded during the entire duration of the test $(60 \mathrm{~min})$ for all the samples were compared. Early test termination criteria is defined by BS 8414$1: 2015+\mathrm{A} 1: 2017$ standard.

\subsection{5 min' Duration}

In Table 4, the temperature results during the first 15 min are listed for each sample. Although the temperature and time have been measured at both, L1S and L2_S, L2_C and L2_I, thermocouples at the first level are not taken into consideration in this group of results because the test criterion for the sample failure according to BR135 is defined by temperatures only at the second level.

\footnotetext{
${ }^{2}$ Limited combustibility is a term used in the United Kingdom and is defined in Table A7 of the ADB in relation to national and European standards. ADB notes that, for the purpose of ADB, material classified as A2 in the corresponding European test standard EN 13501-1 (or the national standard also listed in Table A7) is also acceptable as a material of limited combustibility.
} 


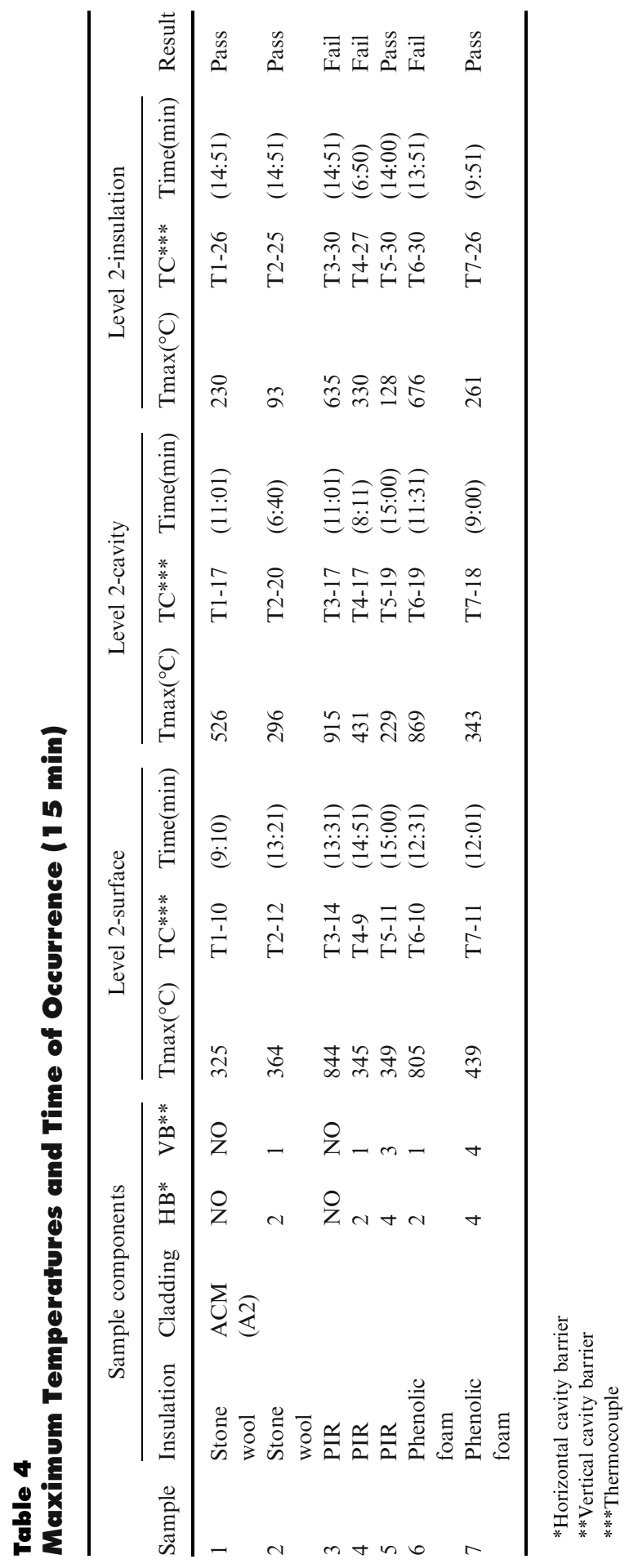




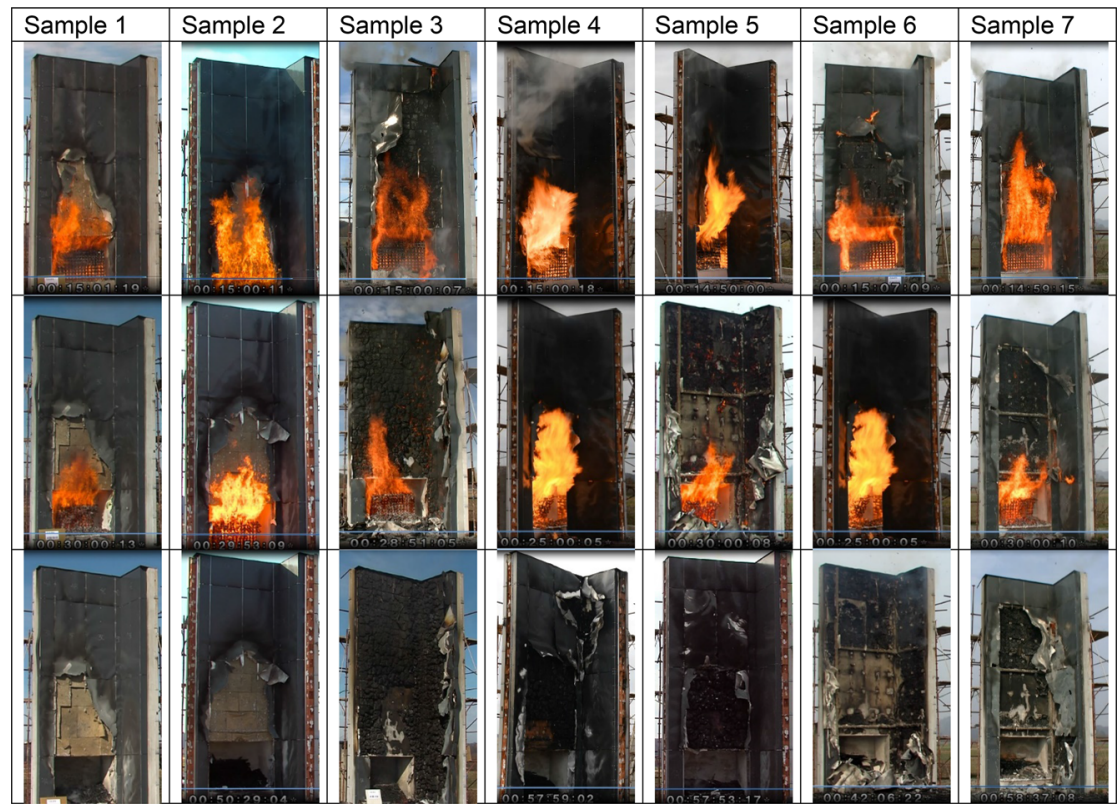

\section{Figure 4. Samples after $15 \mathrm{~min}$ (row 1), $30 \mathrm{~min}$ (row 2) and after the testing (row 3).}

Following the performance criterion, Samples 3, 4 and 6 did not pass the test. For Sample 4, the test failed according to the early termination criteria in BS 8414-1:2015 + A1:2017: "The test shall be terminated if: a) flame spread extends above the test apparatus at any time during the test duration". For Samples 3 and 6 Fig. 4 flame above the top occurred after $15 \mathrm{~min}$ from ignition but had already failed due to the temperature criteria, where we recorded temperatures over $600^{\circ} \mathrm{C}$ level two in all cross-sectional layers during the first $15 \mathrm{~min}$.

Analysing these results and by comparing the impact of insulation for each set of Samples (stone wool/PIR/phenolic foam), it can be noticed that in case of combustible insulation, two horizontal barriers are insufficient to prevent the fire propagation (Sample 4) and the temperature can rise above $600^{\circ} \mathrm{C}$ (Sample 6). Moreover, for both samples higher temperatures were first recorded in the cavity layer and then in the insulation. For Sample 4, inadequate number of horizontal barriers may have contributed the progressive vertical flame propagation which allowed the flame appearing above the top of the sample at 27:20 min. For Sample 3 and 6, the lack of vertical barriers on the right side of the chamber contributed to the highest temperature in insulation on the side wall (thermocouples T3-30, T6-30) and not on the main wall. Figure 4 shows the fire spread on the facades after the first 15 and $30 \mathrm{~min}$ of the test duration, as well as after testing.

Increasing the number of horizontal barriers (from 2 to 4 ) can prevent the spread of fire above the top of the test apparatus (Sample 5 and 7) thus allowing the specimen to pass the test. However, for samples with four barriers, the dis- 
tance between the first and second, and the second and third is approximately $250 \mathrm{~cm}$ and between the third and fourth is about $100 \mathrm{~cm}$. For technical and practical reason, this number of fire barriers is recognized as problematic. If we consider a standard residential construction, the minimum vertical distance between the two different storey windows is $120 \mathrm{~cm}[29,30]$. Setting four horizontal barriers in $1.20 \mathrm{~m}$ to prevent the fire spread between two floors is unsustainable and it is not standard practice.

\subsection{0 min' Duration}

In this section, we will observe fire propagation of the three groups of insulants (group 1, group 2, group 3). Table 5 show for each sample the maximum temperature results observed during the 60 min' test duration. The time values are shown in minutes in relation to the moment of heat source ignition and not the ts which is standard start for sample evaluation. The rationale for this is to clarify the sample behaviour in real fire scenario from the very beginning.

In following graphs, the thermocouple symbol (Figs. 5, 7, 10) is Tx-n, where $\mathrm{x}$ represents the Sample number, and $\mathrm{n}$ the thermocouple position where the maximum temperatures (from the moment of heat source ignition) occurred. Since the samples were not examined at the same day and in the identical weather condition, it has no benefit to compare the same thermocouples of different samples because fire spread is always different. After 5 min of temperature calibration, the heat source was ignited and the test has started but $t_{s x}$ represents the reference start time for the evaluation of sample failure. It is useful to mark the value of " $t_{\mathrm{sx}}$ " for each sample because it shows required time to exceed the temperature of $200^{\circ} \mathrm{C}$ on the first level.

To describe a thermocouple position, following terms will be used:

L1_S - level 1 surface

L2_S - level 2 surface

L2_C - level 2 cavity

L2_I - level 2 insulation

4.2.1. Group 1: Stone Wool Insulation The diagram in Fig. 5 shows the differences in developed temperatures for the use of barriers (Sample 2) and without the use of barriers (Sample 1). Regardless of the use of horizontal barriers, the maximum temperatures which appeared on L1_S and L2_S are approximately the same (Table 5). But on L2_C, without the use of a horizontal barrier in Sample 1, the flame reached the temperature of $526^{\circ} \mathrm{C}$ in 15 th minute, while for Sample 2 the temperature is two times lower.

The influence of horizontal barriers was observed by comparing the maximum temperature in L2_C that appears in the Sample 1 without horizontal barrier $\left(\mathrm{T}_{\max (\mathrm{t}=15: 11)}=526.46^{\circ} \mathrm{C}\right)$ with the temperature on Sample 2 on the same thermocouple $\left(\mathrm{T}_{(\mathrm{t}=15: 51)}=215.6^{\circ} \mathrm{C}\right)$ which is two times lower. The effect of buoyancy is dependent on the amount of surrounding 'fresh air' entrained through the cav- 


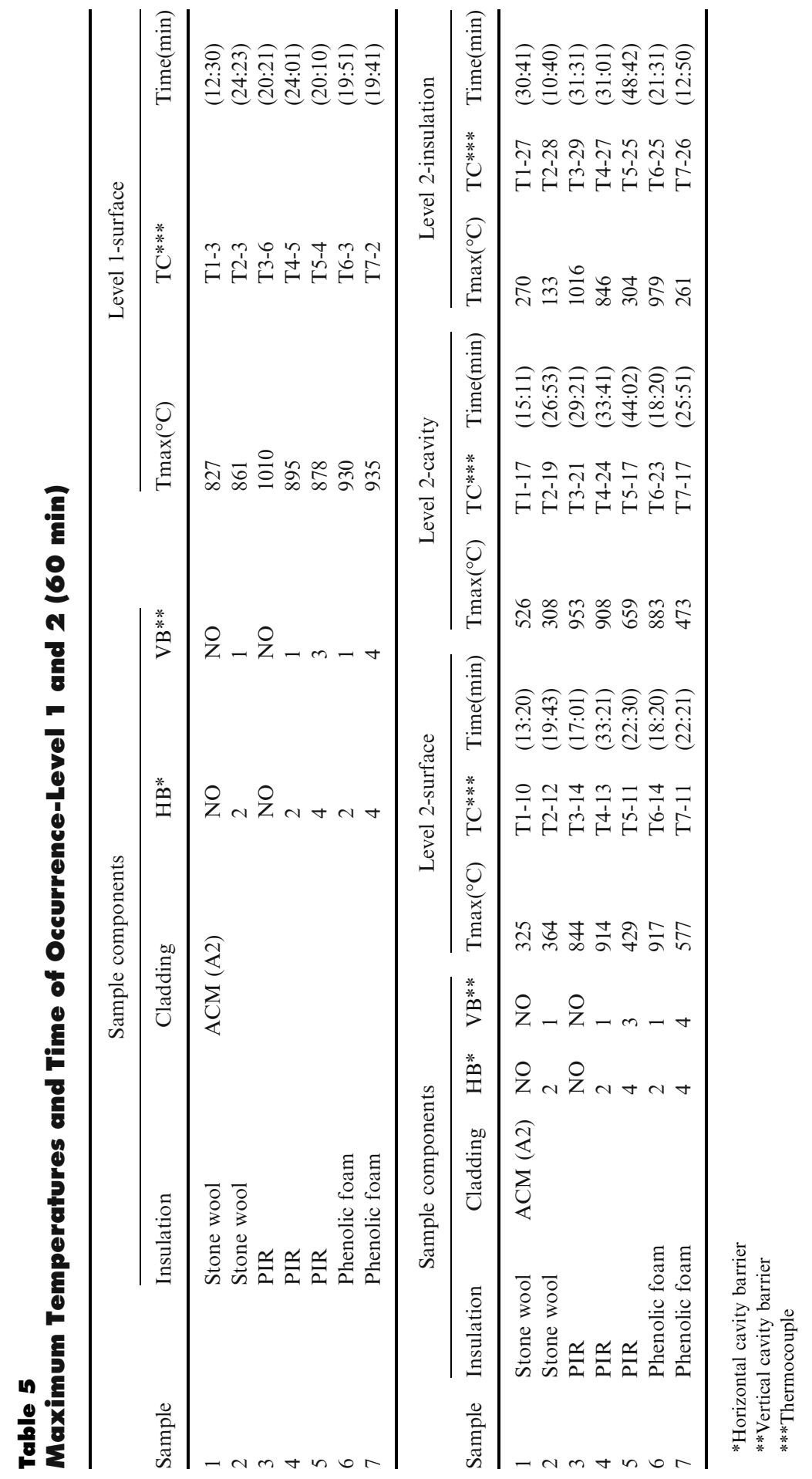




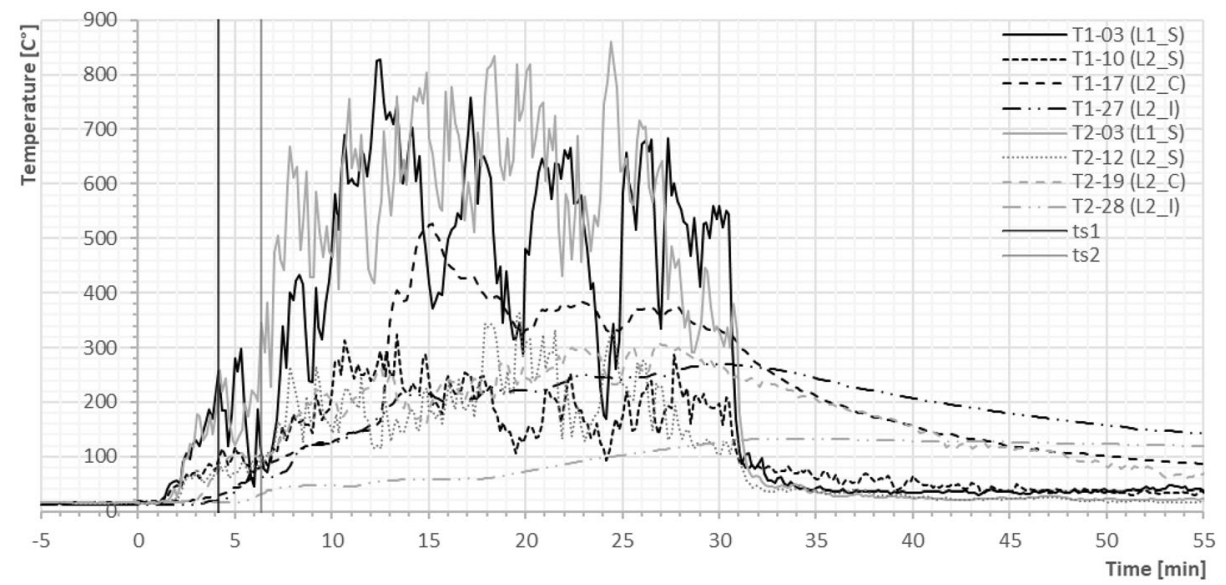

\section{Figure 5. Temperature development in 60 min on thermocouples} with Tmax for both levels-Sample 1 and 2.

ity with hot gases. The ambient temperature of Sample 1 was $15,1^{\circ} \mathrm{C}$ and for Sample $213.6^{\circ} \mathrm{C}$ which at the position of the ignition (chamber) makes similar initial conditions. The temperature difference between L1_S and L2_S for Sample 1 is $323.36^{\circ} \mathrm{C}$ (thermocouple T1-9-T1-1), and for Sample 2 it is $172.26^{\circ} \mathrm{C}$ (thermocouple T2-9-T2-1). The bigger difference in temperatures leads to the bigger difference in the pressures affecting the force of the buoyancy. Since the temperature in the cavity at the first level was not measured, the buoyancy is observed in correlation with the surface and it is expected that the fire propagation in narrow "unprotected" cavity in Sample 1 has been supported by the chimney effect because the air density differences on level 2 and level 1 resulted from temperature differences. In Sample 2, the chimney effect is physically disabled with the hori-

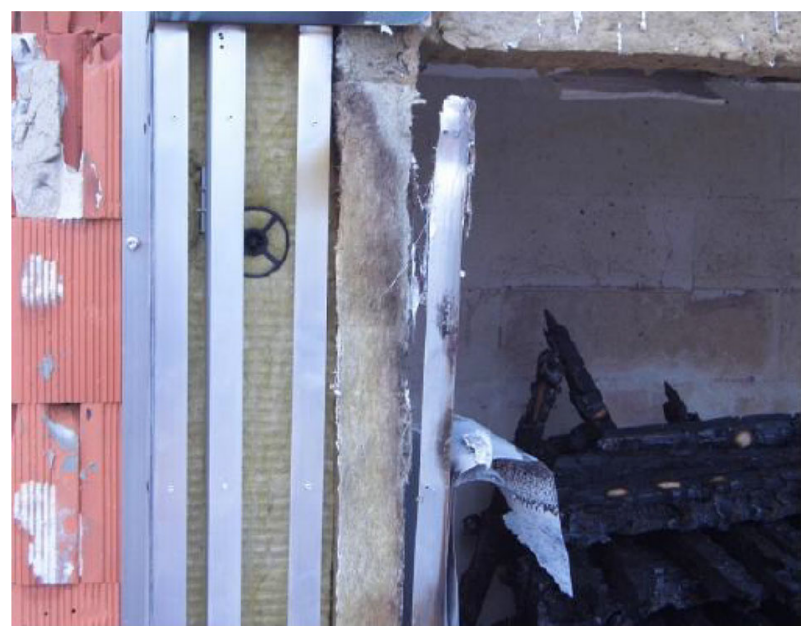

Figure 6. Sample 2- influence of vertical barrier on fire spread. 
zontal barrier and the flame cannot spread easily to the second level at the same moment. The maximum temperature in L2_C of Sample 2 is $308^{\circ} \mathrm{C}$ but compared to Sample 1 reaching the maximum was delayed for another $10 \mathrm{~min}$. All maximum temperatures were measured on the main wall.

By visual analysis of samples after the test Fig. 6 it was noticed that the presence of a vertical barrier had an impact on fire spread and contributed to the safety of the insulation on the left side of the chamber, behind the vertical barrier which remained undamaged.

4.2.2. Group 2: Polyisocyanurate Insulation Panels We have compared samples 3, 4 and 5, as they all have same insulation and cladding. However, they had different number of horizontal barriers (no barrier, two and four barriers respectively).

If we observe the maximum temperatures in Fig. 7 at L1_S for all three samples they appear around the centre line of the Sample, on the main wall. Although the peaks (Fig. 7) for all three samples are similar, around $900^{\circ} \mathrm{C}$, it seems that the addition of cavity barriers, especially horizontal, delays the time to reach the peak temperature. For Sample 3, there is no horizontal barrier to prevent the early occurrence of $\mathrm{T}_{\max }$ and heat transfer can increase with larger flame lengths. High temperatures are visible in all layers and the fire spread is assisted by buoyancy which keeps the flame aligned with combustible insulation [31]. This way, upward flame in combination with narrow cavity ensures the effective heat transfer by convection towards the combustible insulation that has not ignited yet. The horizontal barrier is located $30 \mathrm{~cm}$ above the chamber for Sample 4 while Sample 5 has a barrier right at the top of the chamber. The importance of this position can be described with ts $\left(t_{\mathrm{s} 4}=5: 50, \mathrm{t}_{\mathrm{s} 5}=4: 40\right)$. The distanced barrier delayed the beginning of standard testing, and the temperatures higher than $200^{\circ} \mathrm{C}$ at L1_S was reached one minute later. Furthermore, for Sample 4, the delay to reach maximum temperatures in all layers in relation to Sample 5 is apparent.

From these observations, it is assumed that the distanced barrier delayed the spread of fire at L1_S because the flame that spread out of the chamber on Sam-

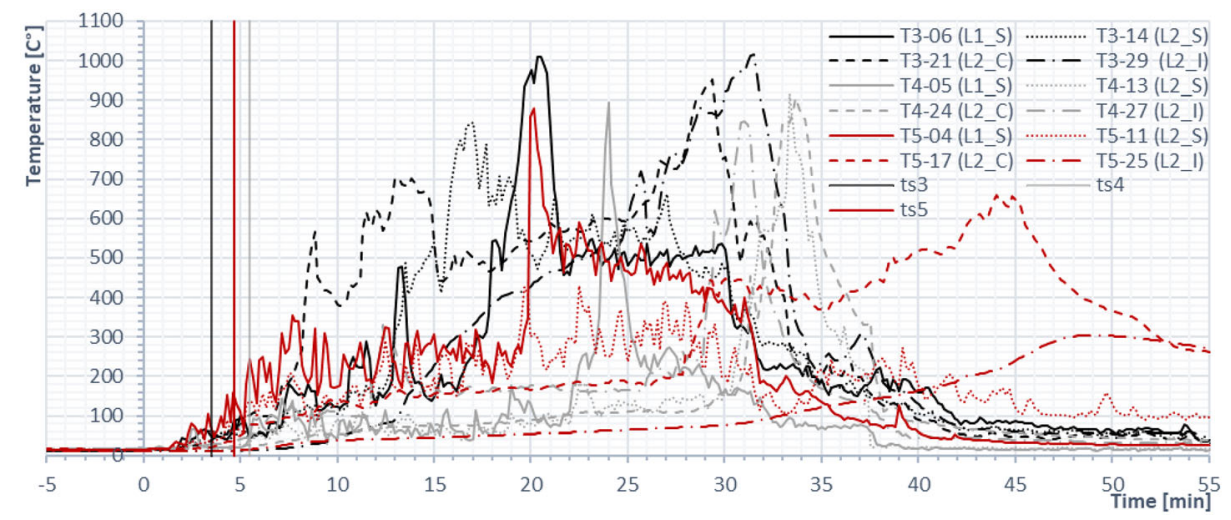

Figure 7. Temperature development in $\mathbf{6 0} \mathrm{min}$ on thermocouples with Tmax for both levels-Sample 3,4 and 5 . 
ple 4 was first "concentrated" on the combustible insulation between the barrier and the chamber. In Sample 5, the barrier immediately prevented the flame penetration in layers behind the surface, and all the flame passed over the surface and directly heated the exposed thermocouples on L1_S. The effect on the higher level (L2_S) was opposite for the sample without the distanced barrier where the temperatures were almost two times lower $\left(429^{\circ} \mathrm{C}\right)$ compared to Sample $4\left(914^{\circ} \mathrm{C}\right)$. Since the flame in Sample 5 was not in touch with the fuel, less volatile fuels were released per unit time due to pyrolysis of combustion insulation which was not significant from the moment of heat source ignition as in Sample 4 where larger amount of fuel resulted in larger flames. In addition, due to the lack of horizontal barrier above the L2_C on Sample 4, it has a two times as high exposed combustible insulation area compared to Sample 5, which also contributed to the conductive heat transfer from the inner layers to the outer surface. The best indicators for this phenomenon are the temperatures in the insulation layer $\left(304^{\circ} \mathrm{C}\right.$ for Sample 5 and $849^{\circ} \mathrm{C}$ for Sample 4).

Visible increase in time intervals for fire to develop to temperatures above $600^{\circ} \mathrm{C}$ for each sample achieved by adding horizontal barriers, indicates their importance in the performance of ventilated façades with combustible polyisocyanurate insulation. Nevertheless, it is important to emphasize that setting four horizontal barriers, is not considered as standard in residential construction.

The influence of the vertical barrier on the left side of the chamber is visually demonstrable. The combustible insulation on the left side of the vertical barrier that was not protected has lost its properties (Sample 3) and it has partially burned out while ones protected by a vertical barrier (Sample 4 and 5) remained undamaged in both cases Fig. 8.

The beneficial effect of a vertical barrier could be seen in Fig. 9 with the graphs of developed temperature on thermocouples in L2_C. Tn-21 is the rightmost thermocouple located on the main wall in L2_C. In relation to Tn-21, Tn-20 is on his left side (main wall) and Tn-22 on the right side (wing wall). For Sample 4, fire curve peaked with $775.6^{\circ} \mathrm{C}$ on the main wall with almost repeated temperature value with the delay of $3 \mathrm{~min}$ on the wing wall. For Sample 5, where the vertical barrier was used on the right side of the chamber, the maximum temperature on the left side of barrier (T5-20) was almost two times higher than the temperature developed on the right side of the barrier (T5-22 on the wing wall). The vertical barrier effectively prevented further horizontal spread of fire by cavity layer maintaining the temperature on the main wall until the end of the test, while for Sam-
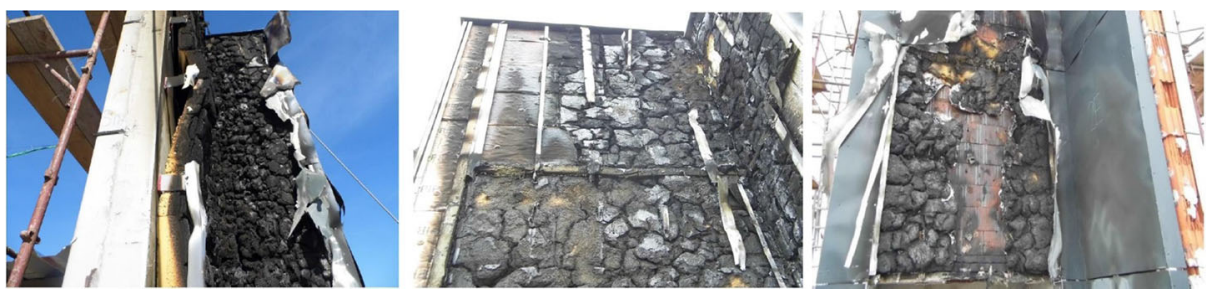

Figure 8. Sample 3,4,5-influence of vertical barrier on fire spread. 


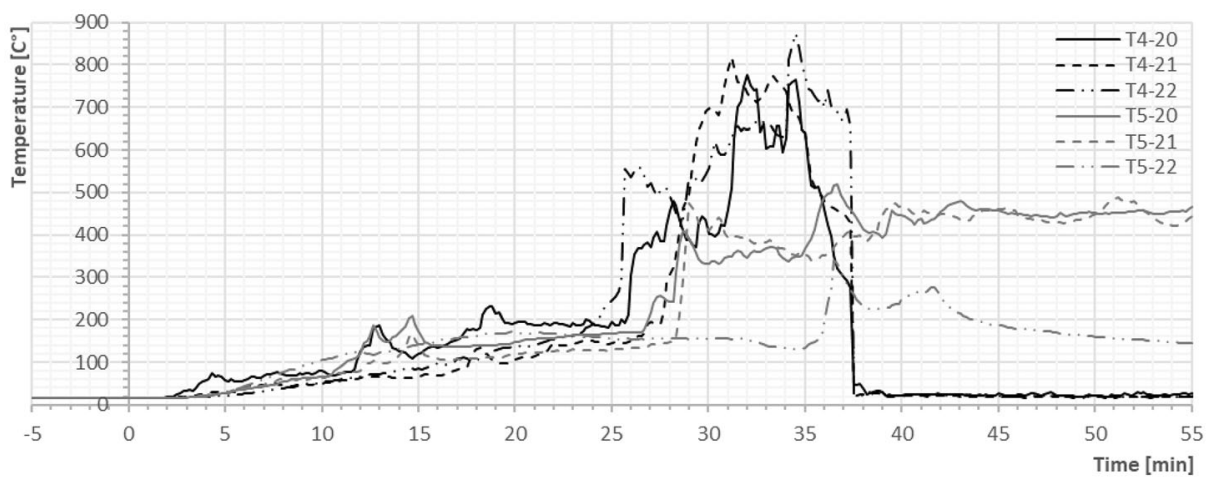

\section{Figure 9. Temperature of thermocouple Tn-20-21-22 in cavity for Samples 4 and 5.}

ple 4 without the same barrier, the temperature reached its maximum and began to fall because all insulation in its surrounding had already burned.

4.2.3. Group 3: Phenolic Foam Insulation Panels Samples 6 and 7 have a different number of vertical and horizontal barriers but the same insulant, phenolic foam. Similar maximum temperatures $\left(\approx 935^{\circ} \mathrm{C}\right)$ were measured after about $19 \mathrm{~min}$ at L1_S for both samples Fig. 10. The first horizontal barrier is positioned $30 \mathrm{~cm}$ above the upper edge of the chamber for both samples and it is implied that it has affected the starting time of testing ts which is approximately the same $\left(t_{\mathrm{s} 6}=2: 50\right.$ $\left.\min , t_{\mathrm{s} 7}=3: 00 \mathrm{~min}\right)$.

Difference in temperatures at level 2 for samples with different number of barriers can be seen in Fig. 10. The effect of placing the third and fourth horizontal barrier is similar to the ones of the second set of Samples (Sample 4 and 5). The

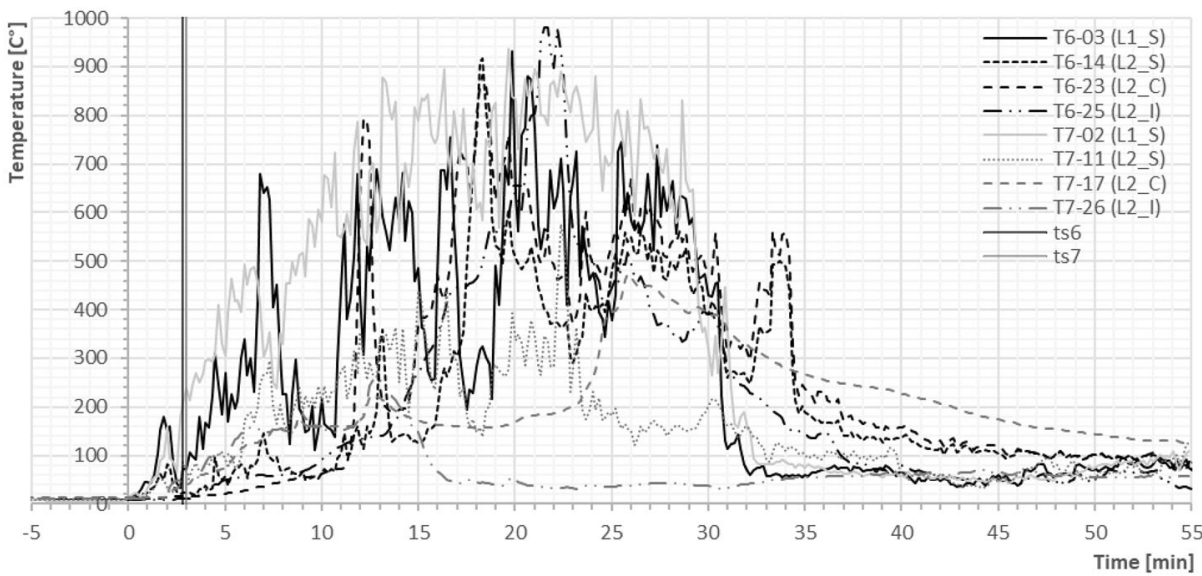

Figure 10. Temperafure development in $60 \mathrm{~min}$ on thermocouples with Tmax for both levels-Sample 6 and 7. 


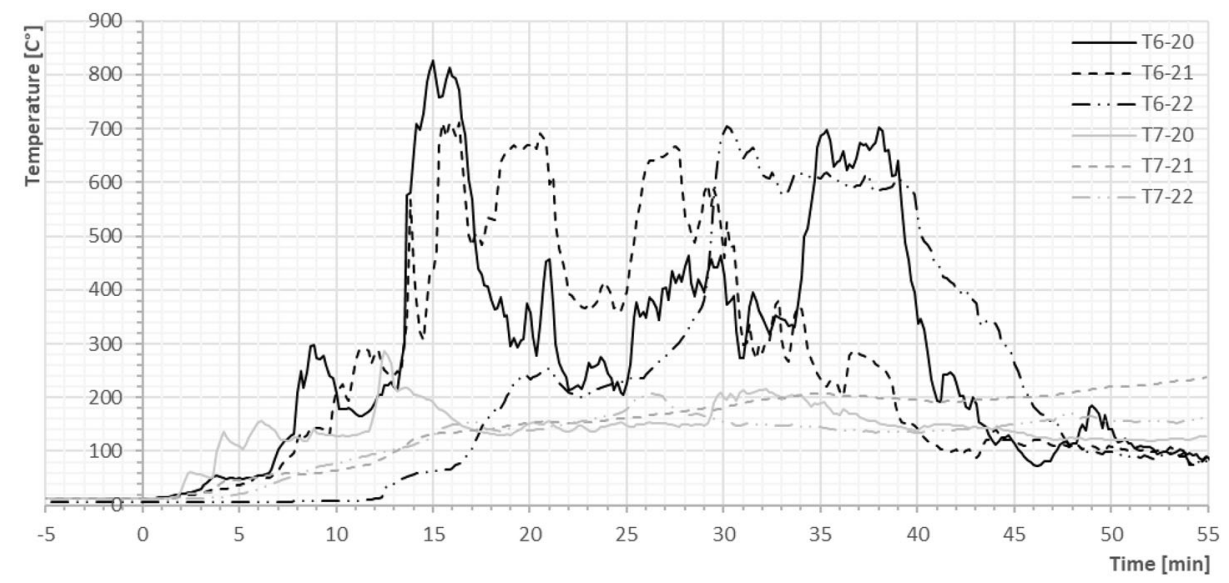

\section{Figure 11. Thermocouple Tn-20-21-22_cavity_Sample 6 and 7.}

lack of third horizontal barrier above the second level of thermocouples on Sample 6, and therefore exposed combustible insulation, contributed to attaining almost two times higher temperatures in the cavity layer and 3.75 times higher temperature in insulation (Fig. 10). By using more than three horizontal barriers in ventilated façades with phenolic foam insulation, one can stop the fire spread and protect other insulation above from burning (Fig. 4, 30 ${ }^{\text {th }}$ minute), but they must be far enough from the source of fire. This behaviour, similar to the second set of Samples, confirms that combustible insulation contributes significantly to the development and spread of fire, and that without proper compartmentalization of ventilated façades with horizontal and vertical barriers, combustible insulation is not recommended for use in high- rise buildings (The comparison of the developed temperatures with the use of a different type of insulation and the same position of the barrier is discussed in later chapters).

Sample 7 has a vertical barrier on the right edge of the chamber that prevents further spread of fire through the cavity. This is proved by the fact that the highest temperature of Sample 6 was achieved on the wing wall in the cavity, and at very high values. However, although the maximum temperatures in Sample 7 are postponed (Fig. 11), there is no significant differences in their value before and after the barrier (T7-20 and T7-22). Thus, we conclude that the vertical barrier is not effective independently of the horizontal barrier as seen in Fig. 12 because despite the use of the vertical barrier on Sample 7, the fire has been jumping from the main wall to the wing wall from the outside. Also, the only protected surface is at the top where is seen the unharmed insulation on the wing wall that was protected by both, vertical and horizontal barriers.

\section{Discussion}

In this section, the Samples with the different insulation materials and the same number of barriers will be compared (group comparison). 

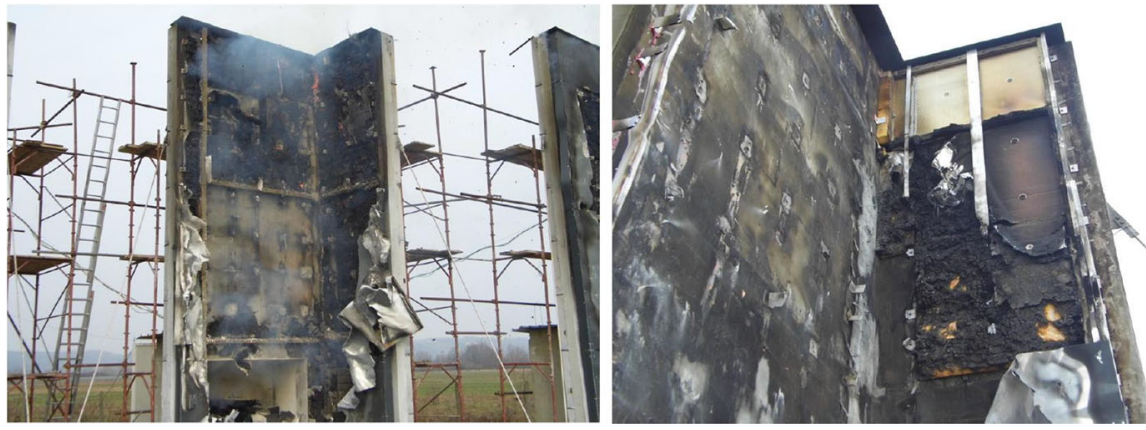

Figure 12. Sample 6 and 7 - influence of vertical barrier on fire spread.

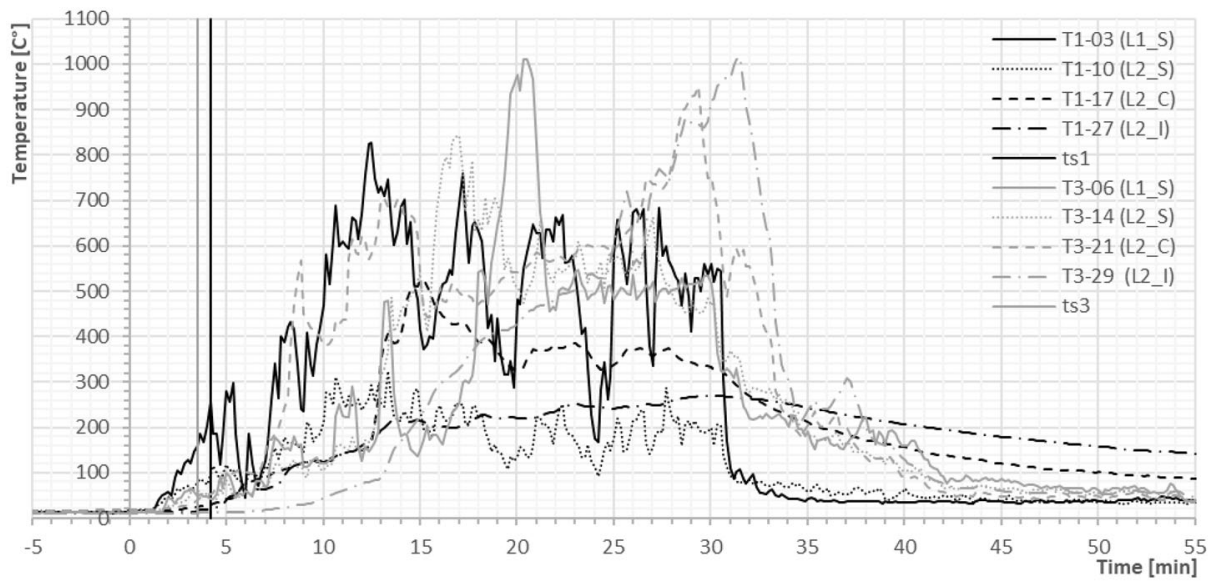

Figure 13. Sample 1 and 3 _Non-comustible and combustible insulation_No barriers_Tmax thermocouples.

\section{Table 6}

The Comparison of the Maximal Temperature for the Same Thermocouple Position-Sample 1, 3

\begin{tabular}{rcccccccr}
\hline $\mathrm{n}$ & Tn-3 & Tn-10 & Tn-17 & Tn-27 & Tn-6 & Tn-14 & Tn-21 & Tn-29 \\
\hline 1 & 827 & 325 & 526 & 270 & 204 & 157 & 292 & 164 \\
3 & 912 & 674 & 920 & 374 & 1010 & 844 & 953 & 1016 \\
\hline
\end{tabular}

\subsection{Non-combustible and Combustible Insulation without Barriers-Sample 1 and 3}

Figure 13 shows the maximal temperature distribution for Sample 1 and 3. Furthermore, Table 6 shows the maximal temperatures values (shown in red) and corre- 
sponding temperatures for the same thermocouples (shown in black) for Sample 1 and 3. By comparing the temperatures for samples with combustible and non-combustible insulation, but without fire barriers (Samples 1 and 3), it can be concluded that the trend of temperature progress at the first level is similar. The maximum recorded temperature is higher in the sample with the combustible insulation like it is shown in Table 6. The impact of insulation combustibility through the development of temperature at the second level is assessed. For all thermocouple positions, the maximum temperatures were higher for Sample 3, with combustible insulation. As both samples do not have open-state horizontal barriers, the temperature in the ventilated cavity layer increased equally in the first few minutes.

However, non-combustible stone wool insulation accumulated part of the energy from the fire and therefore surrounding layers were heated up slower. Meanwhile, in Sample 3, combustible polyisocyanurate insulation ignited and contributed to the rise of the temperature in all layers. The highest difference temperatures occurred is in the insulation layer $-\Delta \mathrm{T}=746^{\circ} \mathrm{C}$. In Sample 3, the insulation completely burned out (shown in Fig. 4).

\subsection{Non-combustible and Combustible Insulation with Two Horizontal and Two Vertical Barriers-Sample 2, 4, 6}

In Table 7 it is shown that the change of the temperatures is similar for all Samples at L1_S, regardless of the combustibility of the insulation. The temperature peaks for Samples 2, 4 and 6 were about $900^{\circ} \mathrm{C}$ and were recorded at similar times, the 24th min from the start of the test for Sample 2 and 4 and 19th min for Sample 6.

The temperature distribution shown in Fig. 14 at the second level in all layers, shows a significant difference in the Sample with non-combustible (Sample 2) and combustible insulation (Samples 4 and 6) for the same position of the first horizontal barrier, at the distance of $30 \mathrm{~cm}$ above the edge of the furnace. In Sample 2, the temperature of the insulation layer did not exceed $135^{\circ} \mathrm{C}$ while in Samples 4 and 6 , temperature values were seven times higher. These differences are shown in Table 7. For the sample with phenolic foam the maximum temperature occurred 6 min earlier than in the sample with combustible polyisocyanurate. Due to the faster burning rate of insulation in Sample 6, the highest temperature in the air cavity occurred earlier, in minute 18, compared to Sample 4 where the maximum temperature was recorded in the minute 33 . Therefore, one should be careful when choosing a type of material due to the difference in fire behaviour of combustible materials.

\section{Table 7} The Comparison of the Maximal Temperature for the Same
Thermocouple Position-Sample 2, 4, 6

\begin{tabular}{cccccccccccc}
\hline $\mathrm{n}$ & Tn-03 & Tn-12 & Tn-19 & Tn-28 & Tn-05 & Tn-13 & Tn-24 & Tn-27 & Tn-14 & Tn-23 & Tn-25 \\
\hline 2 & 861 & 364 & 308 & 133 & 409 & 336 & 141 & 123 & 309 & 194 & 108 \\
4 & 674 & 753 & 116 & 236 & 895 & 915 & 908 & 846 & 868 & 831 & 119 \\
6 & 930 & 665 & 869 & 925 & 632 & 685 & 766 & 873 & 917 & 883 & 979 \\
\hline
\end{tabular}




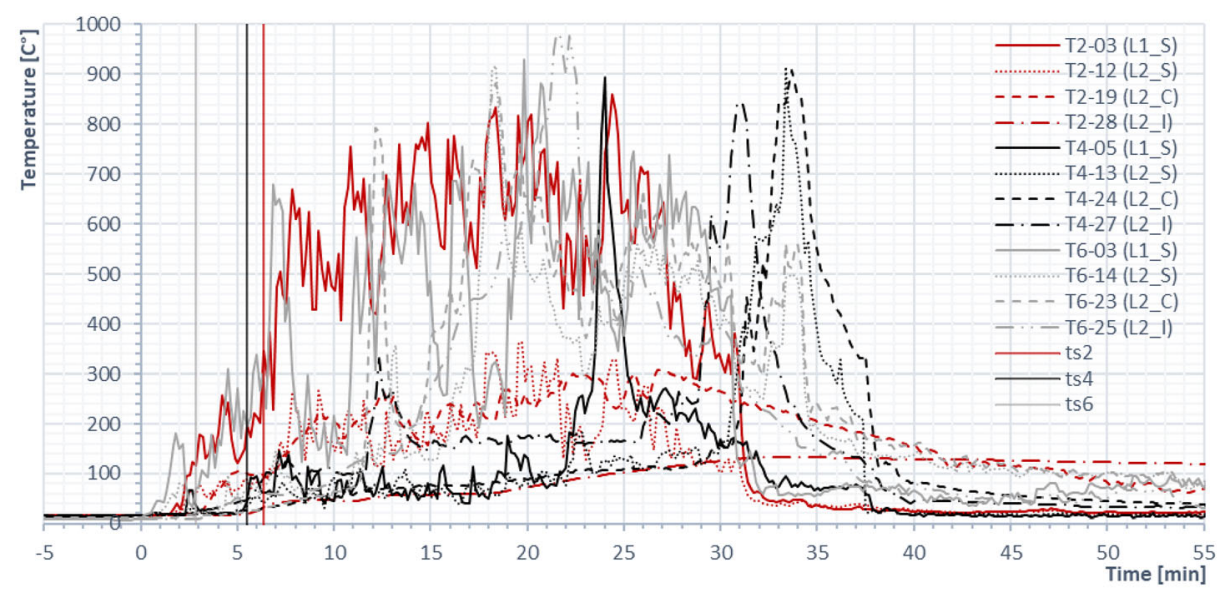

\section{Figure 14. Sample 2, 4, 6-Non-combustible and combustible insulation with two horizontal barriers and two vertical barriers.}

\subsection{Combustible Insulation with Four Horizontal Barriers and Three or Four Vertical Barriers-Sample 5, 7}

Figure 15 shows the temperatures in Samples 5 and 7 with four horizontal barriers and three or four vertical barriers. Both samples have the different type of combustible insulation but similar temperature values at L1_S and L2_S with a somewhat more rapid increase in the temperature for Sample 7 .

The temperatures in the insulating layer are significantly lower than those measured on samples of the same type of insulation but with fewer barriers (Sample 4 and Sample 6). The highest difference between the times in which the maximum temperature occurs for these two samples is in the insulation itself. In Sample 5, the maximum temperature in the insulation of $304^{\circ} \mathrm{C}$, in the insulation layer was recorded in the minute 43 .

Temperatures on $\mathrm{Tn}-17$ in the ventilated air cavity layer have a similar increase up to minute 20 for both samples (Table 8). If the temperatures on L2_C are observed, the PIR shows a better fire performance because with the same number of horizontal barriers, the temperature continues to grow after $44^{\text {th }}$ minute, in contrary to the sample with the phenolic foam that burned down in 12th min. These temperatures are also comparable to Sample 1. By installing only two horizontal barriers and a vertical barrier to non-combustible insulation, Sample 2 has significantly lower temperatures than Samples 5 and 7 with combustible insulation, four horizontal barriers and three or four vertical barriers. Moreover, design for non-combustible insulation is possible and sustainable, and it is not complicated for high buildings, by positioning the horizontal barrier at the top and bottom of the window pane.

For the horizontal barrier behaviour, it is very important to indicate that the level 2 cavity thermocouples were for Sample 5 located below the 3rd horizontal barrier while for Sample 7 thermocouples were just above the 3rd cavity barrier. In BS 8414-1, the level 2 thermocouple location is specified as $5000 \mathrm{~mm}$ above the combustion chamber, according to the scheme in Fig. 17 in "Appendix". 


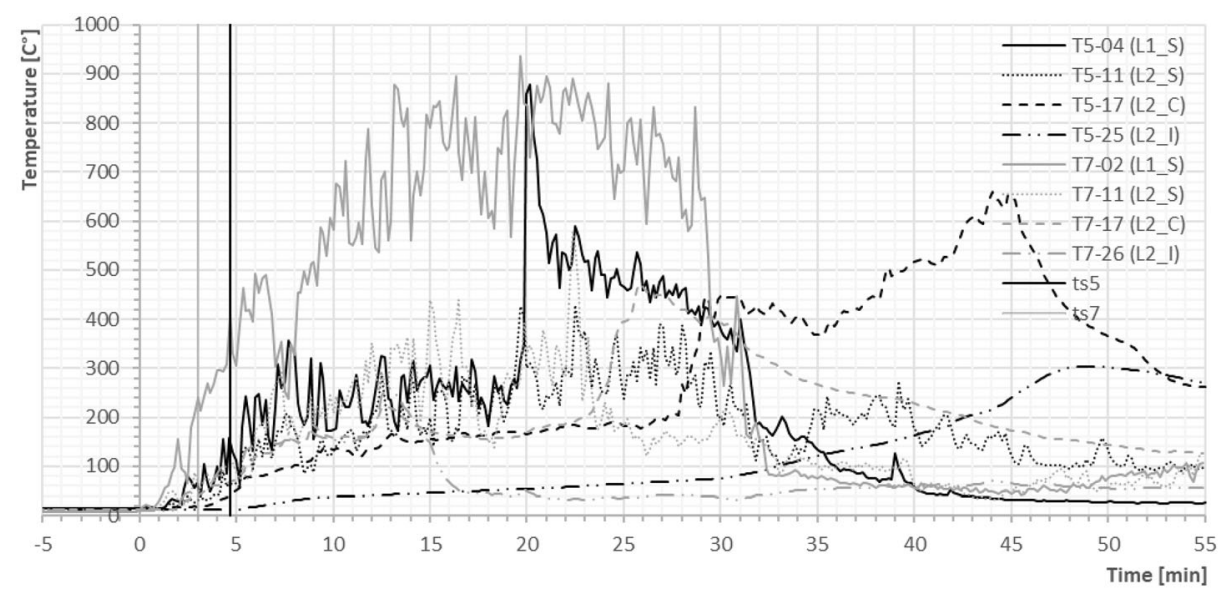

Figure 15. Sample 5,7_Combustible insulation with four horizontal barriers and three (Sample 5)/four (Sample 7) vertical barriers.

\section{Table 8}

The Comparison of the Maximal Temperature for the Same Thermocouple Position-Sample 5, 7

\begin{tabular}{lllllll}
\hline $\mathrm{n}$ & Tn-04 & Tn-11 & Tn-17 & Tn-25 & Tn-02 & Tn-26 \\
\hline 5 & 878 & 429 & 659 & 305 & 846 & 304 \\
7 & 728 & 577 & 473 & 258 & 935 & 261 \\
\hline
\end{tabular}

Figure 16 shows the comparison of the temperatures on thermocouples T5-20 and T7-20 on the main wall before the installation of vertical barrier positioned at the right edge of the chamber. After the installation of the vertical barrier thermocouples T5-22 and T7-22 were mounted on the wing wall. The vertical barrier contributed to the stop of the fire on the wing wall in Sample 5 where the temperature was two times lower than on the main wall. The temperatures that occurred on the right and the left side of the vertical barrier were similar for Sample 7. Therefore, the vertical barrier was inefficient because the fire was spreading over the surface from the main wall to the wing wall assisted by wind direction (shown in 30th min in Fig. 4).

\section{Conclusion}

So far, the importance of vertical and horizontal barriers in ventilated facades has been studied in several research papers which we mentioned in the introduction, but the focus of this paper is on the exact number of fire barriers, their position and the effect on various types of insulation [13-16]. The tests performed for this paper had a full duration of $60 \mathrm{~min}$. This enabled the observation of the complete fire scenario, including the fire growth, possible plateau and decay of the fire dur- 


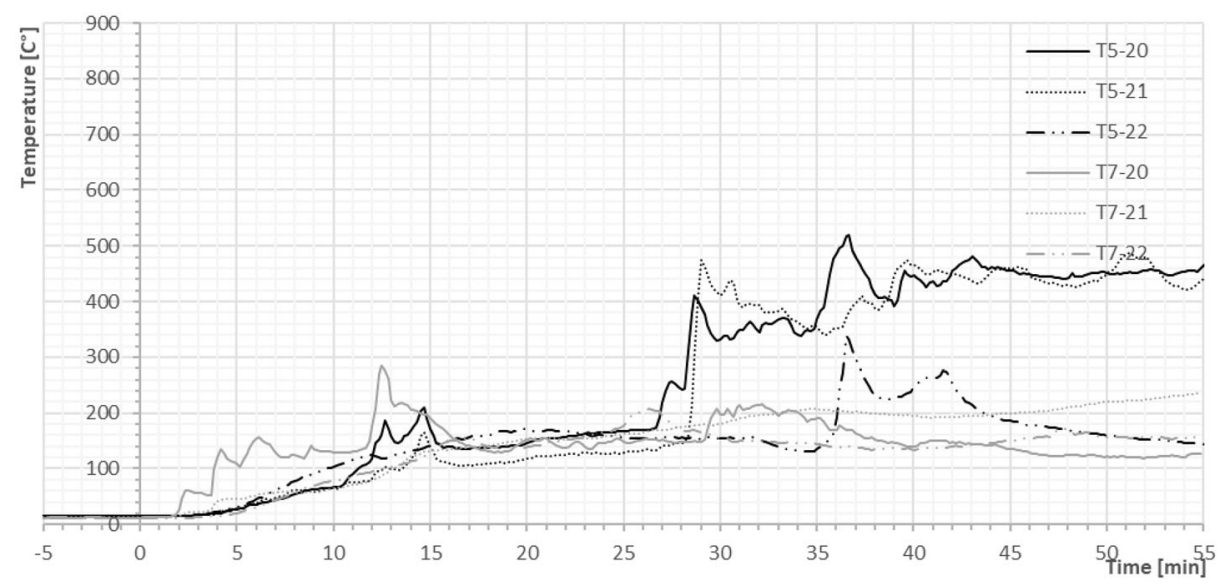

\section{Figure 16. Comparison of temperature distribution around the vertical barrier on the right edge of the chamber -Sample 5 and 7.}

ing $60 \mathrm{~min}$. Proper design allows for the realisation of the primary purpose of the barriers, which is to slow down the fire propagation from one compartment to another and allow the timely evacuation of people.

\subsection{Sufficient Number of Horizontal Barriers}

The tests showed that systems with the combustible insulation and non-combustible, cladding panels are highly dependent on the number of fire barriers in terms of fire propagation. For the tested groups with no barriers, fluctuations in the occurring temperatures are visible, as well as the flame penetration at the top of the sample. For the sample with the combustible insulation, besides the flame propagation to the top of the sample, high temperatures above $900^{\circ} \mathrm{C}$ occurred in the cavity in the first $15 \mathrm{~min}$. In the case of combustible insulation, two horizontal barriers are insufficient in preventing fire propagation when the temperature rises above $600^{\circ} \mathrm{C}$. When there are few fire barriers (three or four), the sample has a much bigger exposed combustible area, which ignition also contributes to the higher temperature on the surface due to radiative and conductive heat transfer. Facades with combustible insulation passed the test conditions only when using four horizontal barriers reaching temperatures that are similar to the temperatures of the sample with non-combustible insulation and no fire barriers. By adding only two horizontal barriers to non-combustible insulation, the highest temperature that occurred in the sample is 1, 5-2 times lower compared to the samples with combustible insulation and four horizontal barriers. Increasing the number of horizontal barriers (from two to four) could prevent the spread of fire above the top of the test apparatus, thus allowing the sample to pass the test.

\subsection{Position of Horizontal Barriers}

Installing the barrier at the top, or the edge of the chamber, delays the fire propagation in the cavity and the insulation layer, since the flame is in touch with the fuel 
from the moment of the heat source ignition, reducing the initial fire load in time if the cladding is not combustible. For three typical fire spread scenarios [30], the position of horizontal barrier right at the top of the window is recognized as important for an internal fire that has started in a compartment inside a building and spreading through openings in the façade (windows, doors etc.) onto higher or lower floors. Barriers' contribution to fire safety of facades is also limited for two other scenarios: when fire spread of the external fire is caused by radiation from the neighbouring building or when the source of fire is located next to the façade, with the consequence of radiation or direct exposure to fire (for example, on litter on the balcony, or on parked cars). Another limitation is that horizontal barriers cannot have a major contribution in preventing the fire spread if the cladding of the façade is combustible because the fire progresses on the external surface.

For samples with four barriers, the distance between the first and second, and second and third fire barrier is approximately $250 \mathrm{~cm}$ and between the third and fourth about $100 \mathrm{~cm}$. The use of barriers to such an extent is not a typical set up that could be seen on a construction site. Installing four horizontal barriers,like in this paper, with a distance of $120 \mathrm{~cm}$ between the two different storey windows in the standard residential buildings would cover $25 \%$ of the area. Furthermore, for the tested samples, the distance between the first and the last (fourth) horizontal barrier is $6 \mathrm{~m}$, which is not the standard height of the floor. Therefore, one of our specific recommendation is to make the fire scenario used for BS 8414 more representative of the reality. An important aspect for the subject of cavity barriers, is that façade tests should include windows which assures that the position of any cavity barriers is identical to the one in the façade design used in standard buildings. It would also be important to include a failure criterion, such as "any fire penetration through cavity barriers incorporated within the cladding system, or around them through breaches in the external cladding panels". Accordingly, thermocouples should be placed below and above the horizontal barrier to monitor their impact as it has been done in this paper for vertical barriers. When thermocouples are too close under the cavity barrier, heat accumulates and the result can be modified. The same misleading effect can appear when the thermocouples are positioned right above the horizontal cavity barrier and in this case the temperatures can be underestimated.

\subsection{Influence of Vertical Barriers}

For non-combustible insulation, all the maximal temperatures were measured on the main wall. Vertical barriers performance were verified by examining the samples after the test, where insulation behind the vertical barriers remained undamaged. For samples with combustible PIR insulation, the temperature was two times as low on the wing wall than on the main wall. However, for the phenolic foam insulation, despite the delayed temperatures on the wing wall, temperatures were similar to those on the main wall. It is assumed that the wind direction had a great impact on these results and assisted the flame propagation from the main wall to the wing wall across the surface. The surface that had both the vertical and the horizontal fire barriers was protected from the flame and was not damaged. 


\subsection{The Relationship Between Fire Resistance of the Insulation and the Number of Barriers}

For samples without expandable horizontal barriers (combustible or non-combustible insulation), the fire propagated through the ventilated air cavity layer and in the first few minutes, and the temperature rate increased almost equally. However, non-combustible insulation accumulated part of the heat, which delayed the increase of the temperature in other layers. Meanwhile, combustible polyisocyanurate insulation ignited and released the volatile fuels due to pyrolysis. During that process, the temperature rose in all the other layers. The temperature in combustible insulation was four times higher, reaching $\Delta \mathrm{T}=750^{\circ} \mathrm{C}$. When using two horizontal barriers, the temperatures were six times higher when combustible insulation was used than when the non-combustible insulation was used. However, there were also differences between combustible insulation, because despite the similar maximal temperatures in the cavity, for the sample with phenolic foam, maximum temperature was reached in the 18th min after the heat source ignition, which was $10 \mathrm{~min}$ before the PIR. Therefore, one should be careful when choosing a type of insulation material because combustible materials do not behave equally in the fire. The same behaviour is visible in the samples with four barriers, with the most significant differences in temperatures between two combustible samples occurring inside the insulation. Combustible insulation contributes significantly to the development and propagation of the fire, and without proper compartmentalisation of ventilated façades with horizontal and vertical barriers, the use of the combustible insulation is not recommended for high-rise buildings.

It is essential to continue the research on this topic to verify and compare the results and get the average values, especially because the tests were not repeated, which can lead to uncertain results. Furthermore, this research is only valid for the chosen geometries and the chosen fire barrier placement. Future research would allow an insight into the impact of the fire barriers placed around openings (such as windows) and the difference between the behaviours of the ventilated facades for different fire barrier positions (both vertical and horizontal)., The installation of the fire barriers on-site is of great importance, and time should be spent on properly fixing the details of the fire barriers for optimal performance in case of a fire.

\section{Acknowledgements}

We would like to thank ROCKWOOL International $\mathrm{A} / \mathrm{S}$ for financial support. A.Č. is thankful to Rockwool Adriatic Ltd., Anđelka Toto-Ormuž and all the other people responsible for the provision of a scholarship for postgraduate studies in Fire safety engineering at the University of Zagreb. A.C. would also like to extend the deepest gratitude to a colleague Mergim Gaši from the Department of Materials of the Faculty of Civil Engineering, University of Zagreb and the employers of the laboratory who contributed with their own time to help us with the work. The work is a result of the collaboration between the Faculty of Civil Engineering at the University of Zagreb and the laboratory for thermal measurements in Croatia. The experimental design and procedures, together with data analysis and the writing of this manuscript were agreed by the authors. 


\section{Open Access}

This article is licensed under a Creative Commons Attribution 4.0 International License, which permits use, sharing, adaptation, distribution and reproduction in any medium or format, as long as you give appropriate credit to the original author(s) and the source, provide a link to the Creative Commons licence, and indicate if changes were made. The images or other third party material in this article are included in the article's Creative Commons licence, unless indicated otherwise in a credit line to the material. If material is not included in the article's Creative Commons licence and your intended use is not permitted by statutory regulation or exceeds the permitted use, you will need to obtain permission directly from the copyright holder. To view a copy of this licence, visit http://creat ivecommons.org/licenses/by/4.0/.

\section{Appendix}

See Tables 9, 10, 11 and Fig. 17.

\section{Table 9 \\ Position of Horizontal Barriers in Relation to the Top of the Combustion Chamber}

\begin{tabular}{lllll}
\hline $\mathrm{a}(\mathrm{cm})$ & 1st & 2nd & 3rd & 4th \\
\hline Sample 1 & - & - & - & - \\
Sample 2 & 22.5 & 300 & - & - \\
Sample 3 & - & - & - & - \\
Sample 4 & 30 & 320 & - & - \\
Sample 5 & 0 & 262.5 & 523 & 613.5 \\
Sample 6 & 30 & 308 & - & - \\
Sample 7 & 30 & 243 & 490 & 596 \\
\hline
\end{tabular}

\section{Table 10}

\section{Position of Vertical Barriers}

\begin{tabular}{ll}
\hline Sample 1 & None \\
Sample 2 & On the left edge of the chamber at the full height of the sample \\
Sample 3 & None \\
Sample 4 & On the left edge of the chamber at the full height of the sample \\
Sample 5 & On the left edge of the chamber at the full height of the sample \\
& On the right edge of the chamber at the full height of the sample \\
& On the right edge of the wing at the full height of the sample \\
Sample 6 & On the left edge of the chamber at the full height of the sample \\
Sample 7 & On the left edge of the main wall at the full height of the sample \\
& On the left edge of the chamber at the full height of the sample \\
On the right edge of the chamber at the full height of the sample & On the right edge of the wing at the full height of the sample
\end{tabular}




\section{Table 11}

\section{Horizontal Barrier Details}

\begin{tabular}{|c|c|c|c|}
\hline \multicolumn{2}{|c|}{ Dimension (mm) } & \multicolumn{2}{|c|}{ Fire performance (min) } \\
\hline Cavity & HB plane cavity* & Integrity(E) & Insulation (I) \\
\hline$\leq 300$ & $\leq 25$ & 60 & 60 \\
\hline$\leq 300$ & $26-35$ & 30 & 30 \\
\hline
\end{tabular}

*The width of the air cavity at the HB location

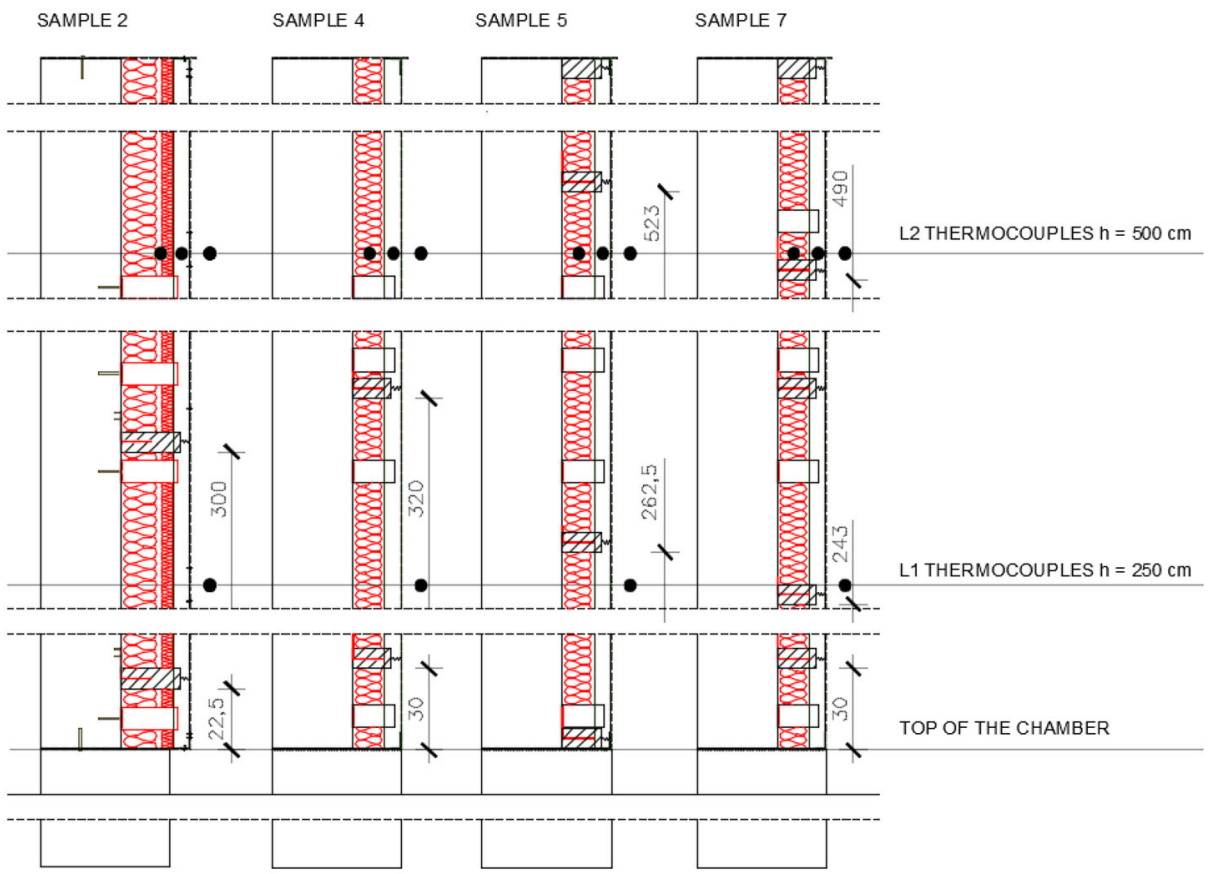

\section{Figure 17. Position of horizontal barriers.}

\section{References}

1. White N, Delichatsios M (2015) Fire hazards of exterior wall assemblies containing combustible components. Springer, London

2. Bisby L (2018) Grenfell tower inquiry Phase 1-Final expert report, pp 1-313

3. Chen T, Yuen A, Yeoh G, Yang W, Chan Q (2019) Fire risk assessment of combustible exterior cladding using a collective numerical database. Fire 2(1):11

4. Peng L, Ni Z, Huang X (2013) Review on the fire safety of exterior wall claddings in high-rise buildings in China. Procedia Eng 62:663-670

5. Genco G (2015) Lacrosse building fire report, vol 2015 
6. Dubai fire - Huge blaze tears through 86-storey Torch Tower apartment block in Marina neighbourhood. [Online]. Available: https://gulfnews.com/uae/fire-at-address-hotel-o n-new-years-eve-caused-by-electrical-fault-dubai-police-1.1656786. Accessed 27 May 2019

7. Fire at Address hotel on New Year's Eve caused by electrical fault_ Dubai Police, Accessed on 27 May 2019

8. van Hees P (2016) Development of full-scale façade tests in ISO TC92. In: MATEC Web of conferences, vol 46, p 01005

9. Buc EC Fire testing and fire reality: what do fire tests really tell us about materials?, pp 61-69

10. Giraldo MP, Lacasta A, Avellaneda J, Burgos C (2013) Computer-simulation study on fire behaviour in the ventilated cavity of ventilated façade systems. MATEC Web Conf 9:03002

11. de Boer JGGM, Hofmeyer H, Maljaars J, van Herpen RAP (2019) Two-way coupled CFD fire and thermomechanical FE analyses of a self-supporting sandwich panel façade system. Fire Saf J 105:154-168

12. Guillaume E, Fateh T, Schillinger R, Chiva R, Ukleja S (2018) Study of fire behaviour of facade mock-ups equipped with aluminium composite material-based claddings, using intermediate-scale test method. Fire Mater 42(5):561-577

13. DCLG Test 2 BS 8414-1 2015 + A1:2017 Test. 2017;2:3 August, "BRE Global Client Report," vol 44 (2017)

14. DCLG Test 5 BS 8414-1 2015 + A1:2017 Test. 2017;2:10 August, "BRE Global Client Report," no. 1.2 (2017)

15. DCLG Test 1 BS 8414-1 2015 + A1:2017 Test. 2017;1:27 July, "BRE Global Client Report," no. 1.2 (2017)

16. 25 August; DCLG Test 6 BS 8414-1 2015 + A1:2017 Test. 2017;6, "BRE Global Client Report" (2017)

17. Smolka M et al (2016) Semi-natural test methods to evaluate fire safety of wall claddings: update. MATEC Web Conf 46:01003

18. Anderson J, Boström L, McNamee RJ, Milovanović B (2016) Uncertainties in façade fire tests-measurements and modeling. MATEC Web Conf 46:03002

19. Jeffs GMF, Klingelhofer HG, Prager FH, Rosteck H (1986) Fire-performance of a ventilated facade insulated with a B2-classified rigid polyurethane foam. Fire Mater 10:7989

20. Kolaitis DI, Asimakopoulou EK, Founti MA (2016) A full-scale fire test to investigate the fire behaviour of the ventilated facade system. In: Proceedings of 14th International fire and engineering conference interflam, vol 2, pp 1127-1138

21. Boström L et al (2018) Development of a European approach to assess the fire performance of facades. European Union, 2018

22. http://facade2019.org/

23. Torero JL (2018) Grenfell tower inquiry Phase 1-final expert report, pp 1-181

24. Lane B, Phase 1 report - Section 2 conclusions and next steps, pp 1-89

25. Torero JL (2018) Grenfell tower inquiry: Phase 1 - expert report

26. BS 8414_1_20015_A1_2017.pdf

27. EN 1363-1: Fire resistance tests - Part 1: General Requirements (2012)

28. Government Building Safety Programme-Update and Advice for Building Owners on Large Scale Testing

29. Pravilnik o otpornosti na požar i drugim zahtjevima koje građevine moraju zadovoljiti u slučaju požara, vol 2013. Ministarstvo unutarnjih poslova, Croatia, pp 1-32 
30. Jelčić Rukavina M, Carević M, Banjad Pečur I (2017) Fire protection of facades. University of Zagreb, Faculty of Civil Engineering Zagreb, Croatia

31. Merci B (2018) Fluid mechanics aspects of fire and smoke dynamics in enclosures

Publisher's Note Springer Nature remains neutral with regard to jurisdictional claims in published maps and institutional affiliations. 